\title{
Dynamics of a landscape mosaic: size and age distributions, growth and demography of seagrass Cymodocea nodosa patches
}

\author{
B. Vidondo ${ }^{1, *}$, C. M. Duarte ${ }^{2}$, A. L. Middelboe ${ }^{3}$, K. Stefansen ${ }^{3}$, T. Lützen ${ }^{3}$, S. L. Nielsen ${ }^{3}$ \\ ${ }^{1}$ Limnologisches Institut, Universität Konstanz, Mainaustrasse 212, D-78457 Konstanz, Germany \\ ${ }^{2}$ Centro de Estudios Avanzados de Blanes - CSIC, Camí de Santa Bárbara s/n, E-17300 Blanes, Girona, Spain \\ ${ }^{3}$ Department of Life Sciences and Chemistry, Roskilde University, DK-4000 Roskilde, Denmark
}

\begin{abstract}
The patch dynamics (recruitment, growth and mortality) of seagrass Cymodocea nodosa were examined at the landscape scale (i.e. the scale at which disturbances occur) by means of 3-dimensional ( $X, Y$ dimensions and depth) mapping of shoot internal density and age structure within the basic units (patches) forming the landscape. Highly skewed patch size and age distributions indicated a high exponential patch mortality rate $\left(m=0.82 \pm 0.07 \mathrm{yr}^{-1}\right)$ and a slightly higher exponential patch recruitment rate $\left(1.04 \mathrm{yr}^{-1}\right)$ that ensures the maintenance and fast turnover of this population of patches. Patch growth (i.e. increase in number of shoots per patch) proceeded at an exponential growth rate of $2.28 \pm 0.14 \mathrm{yr}^{-1}$, indicating a doubling time of $111 \mathrm{~d}$ for the shoot population within each patch. Moreover, average patch growth rate accelerates with increasing patch size and age. This selfacceleration of patch growth means that this seagrass species has a remarkable potential for rapid space occupation due to its intense clonal growth. The results obtained emphasize the power of a landscape approach for describing the intense dynamics of colonising seagrass populations.
\end{abstract}

KEY WORDS: Seagrass patch dynamics - Landscape scale - Three-dimensional mapping · Size and age distributions - Pareto distribution

\section{INTRODUCTION}

Landscape ecology studies the processes occurring in the spatially heterogeneous mosaics that compose most ecosystems (Robbins \& Bell 1994, Pickett \& Cadenasso 1995). Evidence of the relevance of landscape ecology to marine environments is rapidly growing. The approach has been successfully applied to seagrass meadows (e.g. Bell et al. 1995, Irlandi et al. 1995).

A detailed examination of seagrass ecosystems reveals a hierarchical arrangement of structure over spatial scales ranging from millimetres to kilometres (Robbins \& Bell 1994). At the millimetre scale, individual shoots are composed of multiple blades with contrasting ages, sizes and epiphytic populations. Shoots are arranged in discrete clumps (at a scale of

\footnotetext{
•E-mail: beatriz.vidondo@uni-konstanz.de
}

centimetres to meters) which, in turn, make up patches (i.e. seagrass beds; 1 to $100 \mathrm{~m}$ diameter). Seagrass beds are arranged into meadows that may extend over kilometre-wide areas (Robbins \& Bell 1994) and often contain important topographic heterogeneity (Patriquin 1975). At the intermediate scale, seagrass beds are often subject to perturbation that creates considerable heterogeneity at scales of several meters and often determines the structure of seagrass landscapes (Duarte 1991). The perturbation is often linked to sedimentary dynamics, such as erosion and burial by migrating sand waves (Marbà et al. 1994, Marbà \& Duarte 1995)

The dynamics of seagrass meadows (growth, grazing, biomass development, flowering, etc.) is often examined by extrapolating processes studied in one or a few small (usually $<1 \mathrm{~m}^{2}$ ) quadrats to the entire meadow. This procedure assumes that all relevant processes influencing the dynamics of seagrass mead- 
ows are contained at scales less than $1 \mathrm{~m}$. This assumption is inconsistent with the biology of seagrasses, which often have physical continuity at scales $>1 \mathrm{~m}$ (e.g. up to $4 \mathrm{~m}$ in Cymodocea nodosa (Ucria) Ascherson; Duarte \& Sand-Jensen 1990a). Their integration over scales greater than $1 \mathrm{~m}^{2}$ means that the plants are not fully dependent on local resource availability.

A proper understanding of the dynamics of seagrass landscapes, therefore, requires sampling at spatial scales large enough to include the dominant processes. Operationally, the landscape scale can be estimated to be about twice as long as the spatial scale at which the dominant processes generating heterogeneity operate, both for designing field work and modelling scenarios (e.g. Duarte 1995). For instance, the subaqueous sand waves that perturb the Cymodocea nodosa population examined by Marbà et al. (1994) are separated by, on average, $21 \mathrm{~m}$. Hence, a sampling area with a characteristic linear dimension of about $2 \times 21 \mathrm{~m}$ would be needed to describe the effect of this perturbation. This sampling scale was approximated by using $100 \mathrm{~m}$ transects in previous studies of the population (Marbà et al. 1994, Marbà \& Duarte 1995). Transect sampling may, however, yield biased results when the processes are not isotropic (i.e. not homogeneous in all directions). This is the case for subaqueous dunes, for instance, which are arrow-shaped structures, rather than having the parallel, linear features assumed by isotropic geometry. Examination of the landscape dynamics of seagrasses, therefore, requires a 2-dimensional analysis that transcends the use of small quadrats or transects.

We believe that an understanding of seagrass meadows dynamics will be limited until the need to consider the landscape as the appropriate scale of analysis is recognised. There are, at present, very few studies on seagrass dynamics at scales that approach that of the landscapes (e.g. Patriquin 1975, Durako \& Moffler 1987, Duarte \& Sand-Jensen 1990a, b, Marbà et al. 1994, Marbà \& Duarte 1995), and even fewer studies provide the 2-dimensional quantitative description of dynamics needed to properly model landscape dynamics. Here we demonstrate the power of 2 -dimensional studies for examining the dynamics of seagrass meadows at the landscape scale. As a model we use a patchy Cymodocea nodosa population, whose life history (Duarte \& Sand-Jensen 1990a, b, Marbà \& Duarte 1995), regulatory processes (Pérez et al. 1994), and perturbation dynamics (Marbà et al. 1994, Marbà \& Duarte 1995) are well understood.

The size and age distribution of patches has been proposed to contain substantial information on the basic dynamics of patchy seagrass populations (Meinesz \& Lefevre 1984, Duarte \& Sand-Jensen 1990a). Previous examinations of seagrass patches have characterised them using only linear dimensions (Meinesz
\& Lefevre 1984, Duarte \& Sand-Jensen 1990a), which do not directly reflect the population dynamics of the seagrass species forming the patches. An alternative, more appropriate approach would be to consider each patch as an independent seagrass population and treat the patches forming the landscape as a metapopulation, with each patch characterised by its population size (i.e. total number of shoots contained). This approach allows us to make at least 2 types of inferences. First, it allows the description of seagrass growth in terms of patch-population growth (i.e. the increase in the number of shoots per patch), rather than in terms of the increase in their linear dimensions, as was done in the past (Duarte \& Sand-Jensen 1990a, Marbà \& Duarte 1995). Second, by scaling the patch abundance to patch size, the fractal dimension of the studied vegetation landscape can be determined and used to establish the characteristic domains of scale of that landscape (Wiens 1989, Zeide 1993, Fonseca 1996). A domain of scale is a given size range characterized by a constant fractal dimension. It implies that similar processes are operating on that scale, such that the landscape exhibits self-similarity in that size range. On the other hand, a change in the fractal dimension along the size gradient is an indication of a shift between controlling processes or constraints and, thus, the existence of a different domain of scale (Schroeder 1991, Meltzer \& Hastings 1992, Hastings \& Sugihara 1993, Robbins \& Bell 1994).

Our goal here is to describe the size and age distribution of the seagrass patches forming the landscape, examine the variability of patch growth, and estimate the basic dynamics of the patches (formation, growth, and mortality rate). We hypothesise that surface patch expansion is not a homogenous process, but it is accelerated by synergism (self-accelerating or positive feedback mechanisms) in this clonal plant, and therefore, we examine how patch size (number of shoots per patch) is related to time (patch age) in order to estimate patch-population growth rate. This synergic process may be reflected in the patch size distribution as changes in the fractal dimension along the size gradient. Thus, we estimate the fractal dimension of this patchy landscape in order to test the existence of a single or several domains of scale (i.e. whether or not the dynamics of big patches differs from the dynamics of small patches).

\section{METHODS}

Study area: the Cymodocea nodosa landscape in Alfacs Bay (NW Mediterranean). The seagrass Cymodocea nodosa grows as scattered patches on a tideless, $4 \mathrm{~km}$ wide, shallow $(<2 \mathrm{~m})$ platform in Alfacs Bay 
$\left(40^{\circ} 36^{\prime} \mathrm{N}, 0^{\circ} 43^{\prime} \mathrm{E}\right.$; NE Spain), where this patchy landscape has existed for at least 2 decades. The $C$. nodosa patches grow over highly mobile subaqueous dunes that migrate at an average velocity of $13 \mathrm{~m} \mathrm{yr}^{-1}$ over the shallow platform from the open bay towards the sand barrier which separates the bay from the Mediterranean Sea (Marbà et al. 1994). A strong coupling between patch dynamics (rhizome elongation rate, vertical shoots growth, flowering frequency) of $C$. nodosa and subaqueous dune migration has been demonstrated, leading to the conclusion that this disturbance caused by migrating sediments maintains the patchy vegetation landscape by keeping $C$. nodosa in a permanent state of colonisation (Marbà \& Duarte 1995).

Landscape mapping. A quadrat of $12000 \mathrm{~m}^{2}(150 \mathrm{~m}$ parallel to the shore $\times 80 \mathrm{~m}$ into the bay), containing several subaqueous sand dunes and many seagrass patches, was established in July 1994 to represent the seagrass landscape adjacent to the inner shore of the bay's sand bar (see Fig. 1). A grid with a resolution of $5 \mathrm{~m}$ longshore and $2 \mathrm{~m}$ offshore was established inside the quadrat, and used to map the bathymetry of the landscape using rulers (resolution $\pm 1 \mathrm{~cm}$ ). The water level at a reference point was measured every 20 min to correct the depth measurements for any changes due to sea level fluctuations inside the bay. Each $5 \mathrm{~m}$ wide offshore transect was then screened to create a vegetation map by noting the position of the patches (resolution $\pm 0.5 \mathrm{~m}$ ) on each transect.

Isolated shoots were dug up to ascertain whether they were seedlings or short shoots stemming from a buried, older rhizome system. The maximum age of all these single shoots was then determined following Duarte \& Sand-Jensen (1990a). Shoot age was estimated as the total number of leaves produced during the shoot life span (i.e. number of standing leaves plus leaf scars from shed leaves). The units used for these age estimates are plastochrone intervals (PIs; Erickson \& Michelini 1957) and can be translated into absolute time by multiplying them by $26 \mathrm{~d}$, which is the mean time elapsed between the production of successive leaves for the Cymodocea nodosa population studied (Pérez 1989, Duarte \& Sand-Jensen 1990a, Marbà et al. 1994).

The surface of patches whose major axis was larger than $1 \mathrm{~m}$ was estimated from measurements of patch dimensions along every $45^{\circ}$ bearing from the geometric centre of the patch, which allowed the identification of the main (i.e. longest) axis and the secondary axis (the longest axis perpendicular to the main axis) We then established transects along the main axis and, for large patches ( $>10 \mathrm{~m}$ across), the secondary axis of the patches in order to locate the position of the oldest shoots and, thus, the origin of each patch (cf. Duarte \&
Sand-Jensen 1990a). We described the age gradient across the patches, which allowed calculation of patch growth rates (Duarte \& Sand-Jensen 1990a) by placing 3 to 16 stations (depending on patch size) uniformly spaced along the transects, and collected the shoots using a $0.0314 \mathrm{~m}^{2}$ corer. The shoots in each corer were counted and aged to identify the age of the oldest shoot present.

For the smaller patches (main axis $<1 \mathrm{~m}$ ) we counted and determined the age of all shoots within the patch. The maximum age obtained represents the time elapsed since the stations were colonised, and the position within each patch containing the oldest shoot was assumed to be at, or close to, the position where the patch was initiated (cf. Duarte \& Sand-Jensen 1990a).

The vegetation within the landscape was mapped using a GIS software (IDRISI Geographical Information System). Data were introduced as different matrices $(150 \times 80$ data points $)$ of depth, presence/absence of seagrass, shoot density, and maximum age. Subsequent bathymetric maps, shoot density maps, and age maps were obtained using the standard procedure of krigging to interpolate the data. The resulting maps were then used to distinguish coalescing patches (i.e. those with more than one age maximum) and to calculate the total number of shoots in each patch by integrating the number of shoots in a given area in the shoot density matrix.

Patch dynamics. The patch size (as number of shoots per patch) frequency distribution was constructed for all patches present within the $12000 \mathrm{~m}^{2}$ mapped area. The patch size distribution was described using a cumulative distribution function of the Pareto distribution (Kotz \& Johnson 1985). The Pareto distribution is widely used in many other disciplines for the description of size distributions in other systems (Winiwarter \& Cempel 1992, Vidondo et al. 1997). The probability density function, $p d f(s)$, of the Pareto distribution is

$$
p d f(s)=\text { const. } s^{-D-1}
$$

In order to fit discrete empirical data to this continuous function it must be integrated along a given size range. Integrating $p d f(s)$ from any given size $S$ to infinity, we obtain the complementary function of the cumulative distribution function with the form:

$$
\operatorname{prob}(s \geq S)=\int_{S}^{\infty} p d f(s) \mathrm{d} s=\text { const. } S^{-D}
$$

where $s$ is the variable patch size, and $S$ is any given size value (Kotz \& Johnson 1985). The probability (prob) that the size (s) of a patch taken at random will be equal or greater than size $S$, prob(s $\geq S$ ), is calculated, for each patch, as the fraction of all patches larger than or equal to itself: 


$$
\operatorname{prob}(s \geq S)=\frac{N(s \geq S)}{N_{T}}
$$

where $N(s \geq S)$ is the abundance of patches larger or equal than a given patch and $N_{\mathrm{T}}$ is the total abundance of patches. Equating Eqs. (2) \& (3), the slope $D$ is obtained by fitting a regression line to the logarithm of the fraction of patches larger than or equal to a given size versus the logarithm of that size,

$$
\log \left(\frac{N(S \geq S)}{N_{\mathrm{T}}}\right)=\text { const }-D \log S
$$

The slope of this regression, $D$, also called patchiness exponent, is a measure of the relative number of small versus big patches and provides is an estimate of the fractal dimension of the vegetation landscape, allowing one to test for self-similarity across scales (Meltzer \& Hastings 1992, Hastings \& Sugihara 1993).

Initial exponential patch mortality rate $\left(m\right.$, in $\left.\mathrm{yr}^{-1}\right)$ was also derived from the patch distribution of patch age, as the slope of the equation

$$
N_{t}=N_{0} e^{-m t}
$$

describing the decline in patch abundance $(N)$ with time (i.e. patch age, $t$, in yr). Patches older than 7 yr were not included in this calculation to avoid the error associated with their rareness. Patch recruitment (as exponential units $\mathrm{yr}^{-1}$ ) was derived as the natural logarithm of the fraction of patches younger than 1 yr.

Patch growth was represented by the rate of rhizome lateral spread, calculated as the age gradient $\left(\mathrm{cm} \mathrm{yr}^{-1}\right)$ between the origin of the patch (i.e. the location of the oldest shoot within the patch) and the oldest of the shoots at the patch edge (Duarte \& Sand-Jensen 1990a). In addition, the rate at which space was being occupied by patches (the surface patch expansion) was estimated from the exponential increase in patch size (as number of shoots per patch as a function of age). Patches older than $7 \mathrm{yr}$ were not included in this calculation to avoid the error associated with their rareness and to take into account the fact that the oldest and biggest patches may no longer have been growing.

Because the seagrass patches studied represent, by and large, single clones (i.e. single individuals), the mortality and growth processes are similar to those influencing the seagrass individuals, for which considerable evidence of exponential processes has been produced (cf. Duarte et al. 1994).

\section{RESULTS AND DISCUSSION}

The $150 \times 80 \mathrm{~m}$ landscape studied contained several subaqueous dunes, which showed considerable topographic complexity (Fig. 1). There were 489 seagrass patches, ranging in size from patches formed by a single shoot to some containing $>3 \times 10^{6}$ shoots. The age of the patches varied from 0.08 to $10.5 \mathrm{yr}$ (Fig. 2). Examination of the age distribution within the patches revealed the 3 largest $\left(>1 \times 10^{6}\right.$ shoots per patch) patches to be composed of multiple coalescent patches, the largest patch found ( $>3 \times 10^{6}$ shoots) consisting of 5 coalesced patches (Fig. 2). The individual patches forming these larger patches were considered separately in the examination of patch size (as the number of shoots per patch) and patch age distributions.

The patch size distribution represented as a cumulative distribution function of the Pareto distribution shows an inflexion point at patches of about $10^{3}$ shoots, indicating the existence of at least 2 different domains
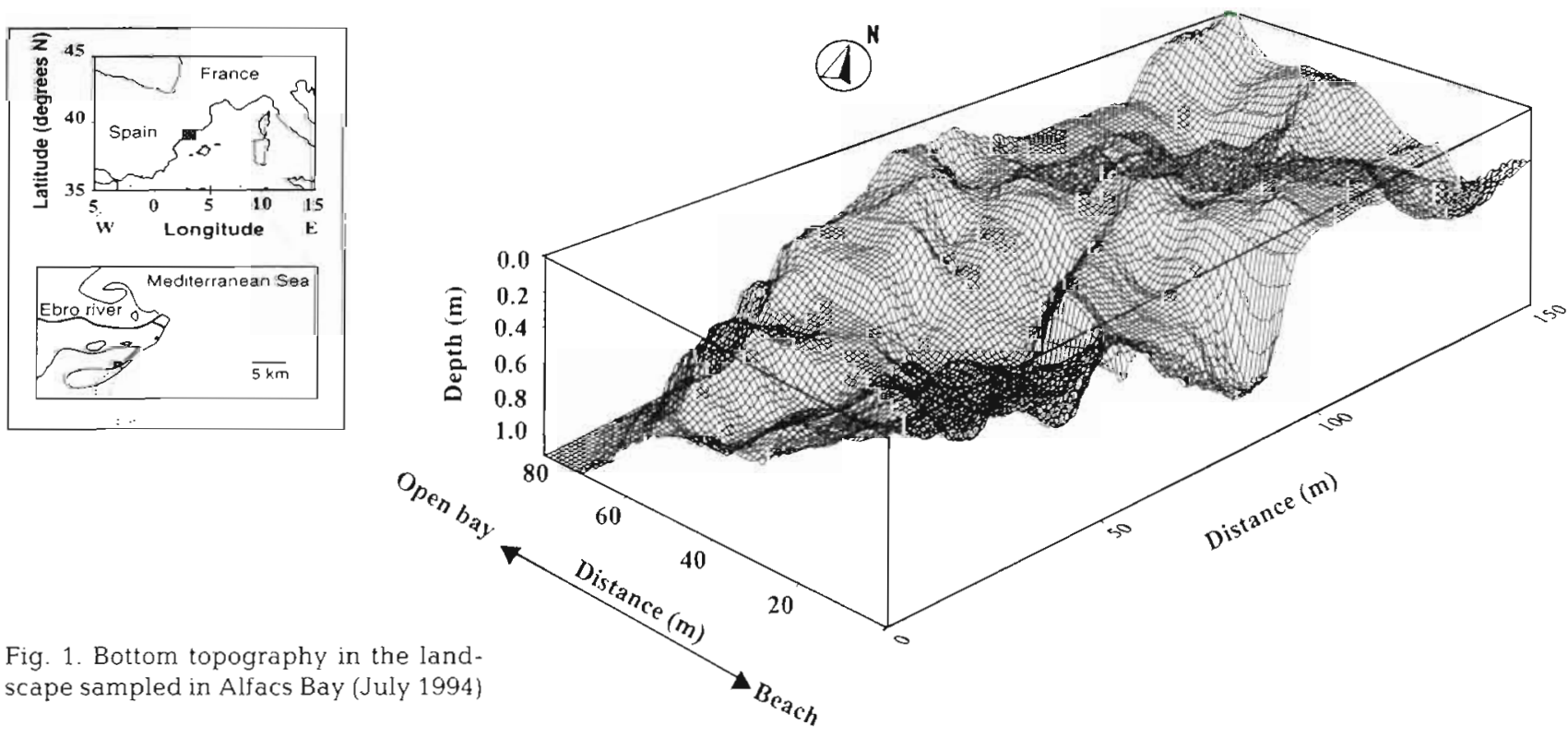

Fig. 1. Bottom topography in the land-
scape sampled in Alfacs Bay (July 1994) 


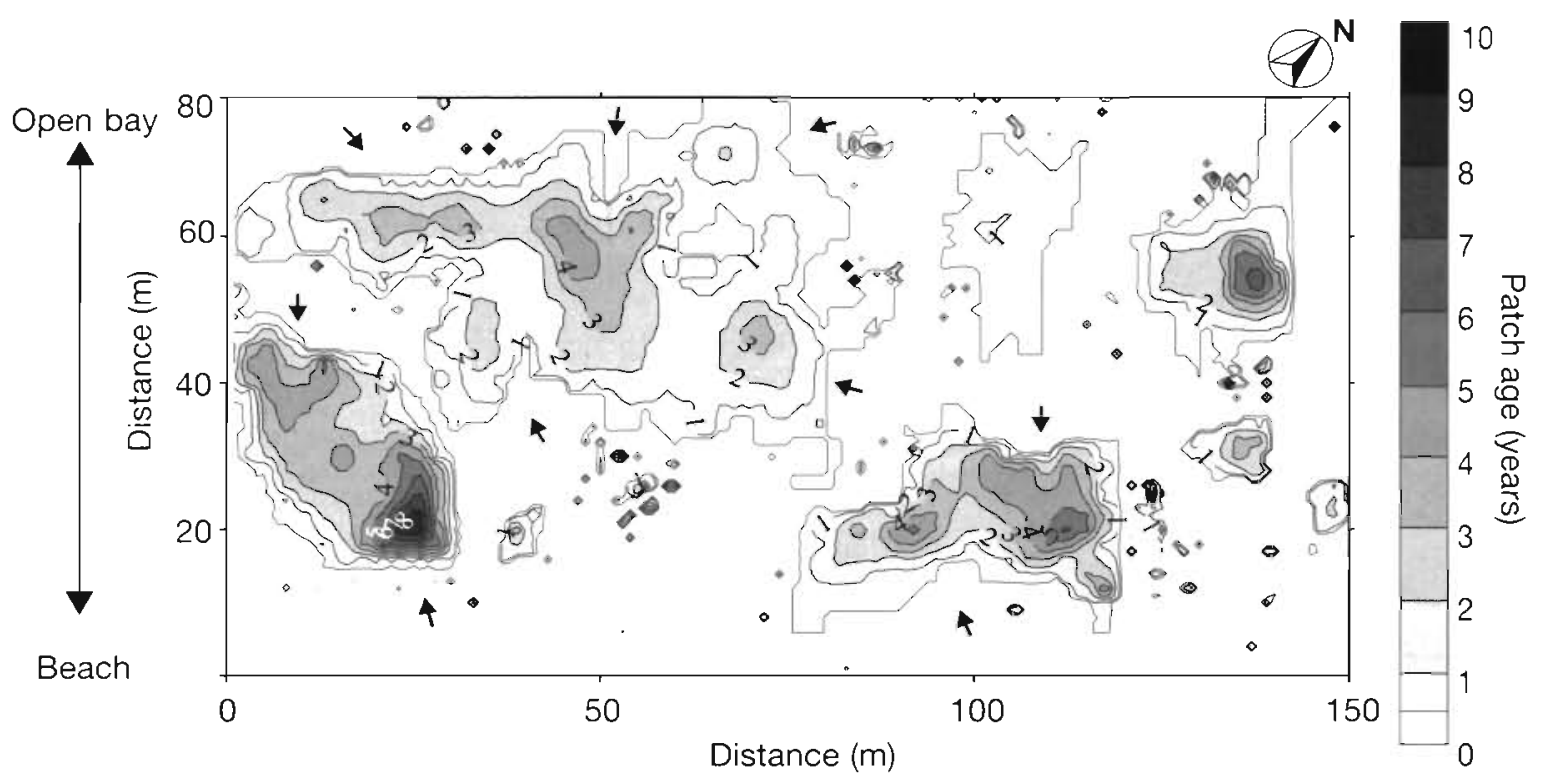

Fig. 2. Distribution of maximum shoot age in the sampling area. Coalescent patches are indicated with arrows

of scale (Fig. 3). Patches smaller than $10^{3}$ shoots fit to a linear Pareto distribution $\left(\mathrm{R}^{2}=0.98, \mathrm{~N}=479\right)$, indicating the existence of a characteristic fractal dimension for this range of patch sizes. Their fractal dimension (or patchiness exponent) ( $D=0.6$, see Eq. 4$)$ is at the upper limit of other patch size distributions of terrestrial vegetation (Hastings \& Sugihara 1993). However, patches larger than $10^{3}$ shoots are more abundant than expected for an entirely self-similar size range, which indicates a size-dependent shift in the processes generating the observed patch size distribution (i.e. growth, mortality).

The patch size distribution (i.e. the frequency distribution of the number of shoots within the individual patches) was highly skewed, indicating fast patch formation and high mortality rates (Fig. 3). Most of the patches (229, Fig. 3) were comprised of isolated shoots, some of which were seedlings derived from reproductive activity in the previous year, and the rest were individual shoots that survived the burial of larger patches. Seedlings younger than 1 yr comprised $65 \%$ of the patches, whereas those older than 1 yr comprised only $9 \%$ of the total number of patches, confirming the very high seedling mortality ( 80 to $90 \%$ annually) previously reported for this location (Duarte \& Sand-Jensen 1990a). Based on the decline in patch abundance with increasing patch age (Fig. 4), the exponential patch mortality rate ( $m$, in Eq. 5) was calculated as $0.82 \pm 0.07 \mathrm{yr}^{-1}$, implying that half of the patches formed die before reaching $0.8 \mathrm{yr}$. This high mortality rate is mostly attributable to the disturbance exerted by the erosion upon the passage of the regressing slope of the sand dunes that transit through this area (Marbà \& Duarte 1995), although the mor- tality of young seedlings may also derive from severe nutrient limitation (Duarte \& Sand-Jensen 1996).

Based on the abundance of new ( $<1$ yr) patches relative to the total number of patches, we calculated a
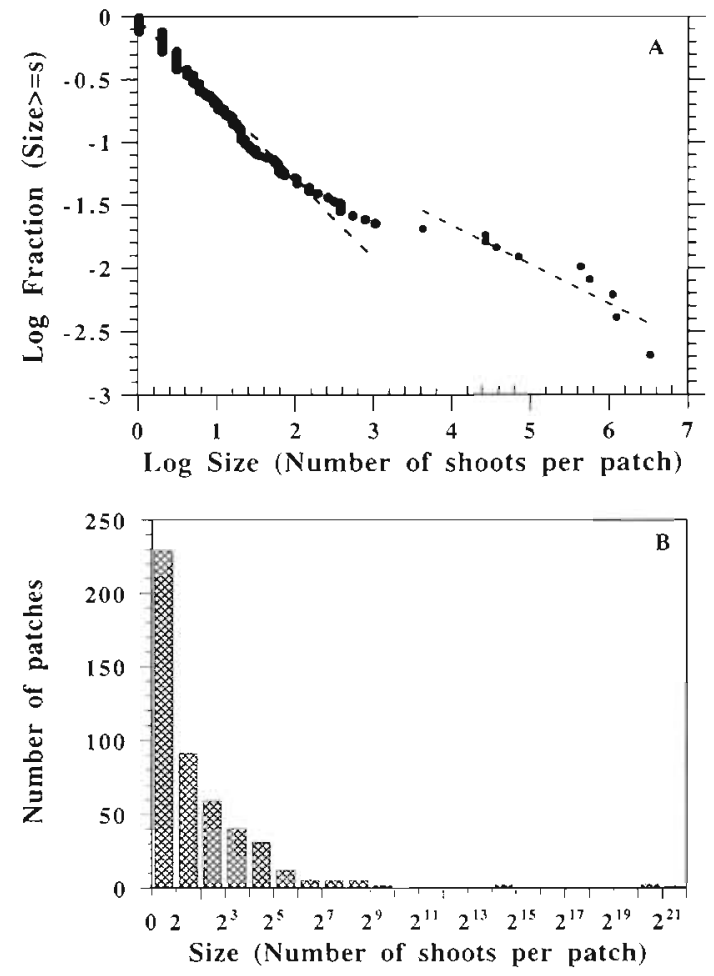

Fig. 3. Cymodocea nodosa. Size distribution of patches in the sampled landscape in Alfacs Bay (July 1994) represented as (A) a cumulative distribution function of the Pareto distribution, and (B) the size frequency distribution of logarithmic (base 2) classes 


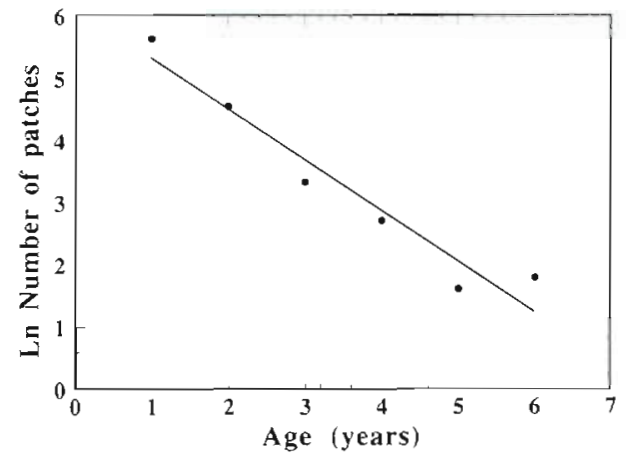

Fig. 4. Cymodocea nodosa. Decline in patch abundance with increasing patch age. The solid line represents the fitted regression equation, ln(number of patches) $=6.134-0.818$ $( \pm 0.07)$ patch age $\left(R^{2}=0.96, p<0.001\right)$

patch recruitment rate of 1.04 ln units $\mathrm{yr}^{-1}$, slightly higher than the mortality rate, ensuring the maintenance of the patch population despite the high mortality rates it experiences. Our estimate of patch recruitment rate $\left(9 \times 10^{-3}\right.$ patches $\left.\mathrm{m}^{-2} \mathrm{yr}^{-1}\right)$ is higher than that reported earlier for this area $\left(4.5 \times 10^{-3}\right.$ patches $\mathrm{m}^{-2}$ $\mathrm{yr}^{-1}$; Duarte \& Sand-Jensen 1990a). However, the latter estimate was derived from sampling at a smaller spatial scale $\left(100 \mathrm{~m}^{2}\right)$, which could result in great variability, considering the patchy distribution of seedlings observed. Examination of aerial photographs reveals that this patchy landscape has existed since 1972, indicating that the observed balance between patch formation and mortality results in a Cymodocea nodosa population which is in a permanent state of colonisation. This state of colonisation represents a dynamic equilibrium that involves a close coupling of the life history of the seagrass and the disturbance they experience (Marbà \& Duarte 1995).

Average patch growth increased with increasing patch size and age (Fig. 5), supporting previous reports that patch growth accelerates during patch expan-

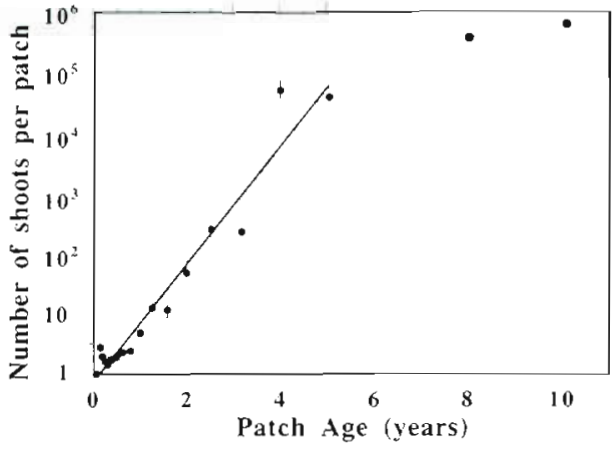

Fig. 6. Cymodocea nodosa. Relationship between the average number of shoots per patch and patch age. Data points represent average values for patch age classes, and bars indicate \pm SE (calculated from logarithmic means). The solid line represents the fitted linear regression equation (Eq. 6 in text) excluding the 2 older patches since they may have no longer been growing

sion (Duarte \& Sand-Jensen 1990a, Marbà \& Duarte 1995)

Patch growth, however, is best represented as the increase in the number of shoots forming the patch (patch size) in relation to time (patch age) (Fig. 6). This relationship between patch size and patch age can be approximated by the regression equation

In patch size $=-0.32+2.28( \pm 0.14)$ patch age $(\mathrm{yr})$

$\left(\mathrm{R}^{2}=0.95, \mathrm{p}<0.001\right)$

For the regression we excluded the 2 older individual patches where the asymptotic patch size had been reached. Thus, the slope of this equation $(2.28 \pm 0.14)$ provides an estimate of the exponential growth rate of the shoot population forming an individual patch. The growth rate obtained indicates a doubling time of $111 \mathrm{~d}$ for the shoot population forming each patch, or the potential to octuplicate population size within a year. The self-acceleration of patch growth is, therefore, conducive to very substantial growth rates of
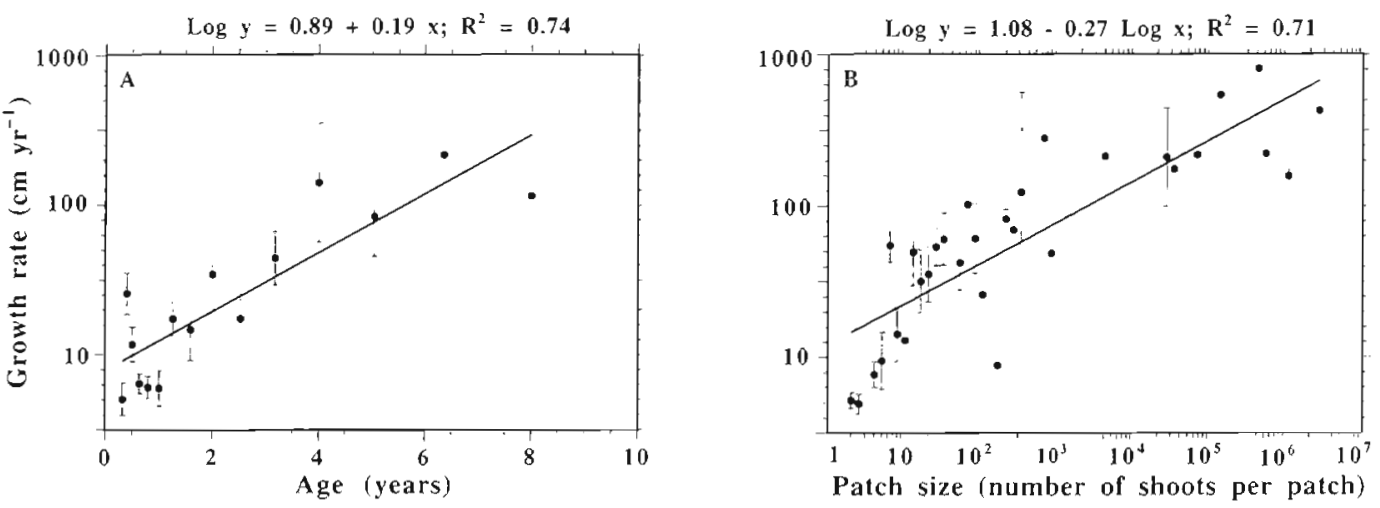

Fig. 5. Cymodocea nodosa. Relationship between patch growth rate ( $\mathrm{cm} \mathrm{yr}^{-1}$ ) and (A) patch age (yr) and (B) patch size (number of shoots per patch). Data points represent average values ( $\pm S E$, calculated from logarithmic means) for size and age classes 
the shoot population, indicating a remarkable potential for rapid space occupation due to the intense clonal growth of this seagrass species. The fact that the patch population is at about steady state at the scale of the landscape despite this substantial growth rate further indicates the large mortality of the patches.

The acceleration of patch growth with increasing age indicates the operation of self-accelerating processes associated with seagrass colonisation, in keeping with the suggestion that seagrasses form a 'mutually sheltering structure' as they grow (McRoy \& Lloyd 1981, Fonseca et al. 1983). The acceleration of patch growth during patch expansion is also expected from the decline in perimeter to area ratio as the patches grow, which may increase the flux of resources along rhizomes from shoots in the inner part of the patches to the rapidly growing rhizomes (runners). The divergence of patches larger than $10^{3}$ shoots, with respect to a linear Pareto size distribution, suggests a reduced mortality of large patches which could be a consequence of the acceleration of patch growth explained here. A positive feedback during macrophyte colonisation has not been observed, however, in other studies of patch growth on eelgrass (Olesen \& Sand-Jensen 1994) or a stream macrophyte (Sand-Jensen \& Madsen 1992). Both of these studies did, however, report lower mortalities of larger relative to smaller patches, presumably due to improved anchoring, mutual physical protection and physiological integration among the shoots as patches grow.

In summary, our analysis of patch recruitment, growth and mortality provides evidence for the power of examining seagrass patch dynamics at the landscape scale, where each patch is considered as a population of shoots, and the set of patches in the landscape considered as a set of populations. By means of this analysis, parameters at the landscape scale that are needed in models to forecast the development of seagrasses are obtained. Examinations at the typical square meter scale would have failed to account for the dynamic turnover of patches, which is the foundation for the dynamic equilibrium which maintains this, and likely other, patchy seagrass landscapes.

Acknowledgements. This study was partially funded by the Spanish Interministerial Commussion of Science and Technology (CICYT - project AMB94-0746). B.V. was supported by a fellowship from the Spanish Ministry of Education and Science and S.L.N. was supported by grant no. SNF-11-0266 from the Danish Natural Science Research Council. We thank M. Pujadas for the advice given about the use of the GIS employed and E. Ballesteros for supplying sampling devices We thank J. Cebrián and M. F. Pedersen for assistance in the field.

\section{LITERATURE CITED}

Bell SS, Hall MO, Robbins BD (1995) Toward a landscape approach in seagrass beds: using macroalgal accumulation to address questions of scale. Oecologia 104:163-168

Duarte CM (1991) Variance and the description of nature. In Cole JJ (ed) Comparative ecology of ecosystems: patterns, mechanisms and theories. Springer, Heidelberg, p 301-318

Duarte CM (1995) Submerged aquatic vegetation in relation to different nutrient regimes. Ophelia 41:87-112

Duarte CM, Marbà N, Agawin N, Cebrián J, Enríquez S, Fortes MD, Gallegos ME, Merino M, Olesen B, SandJensen K, Uri J, Vermaat J (1994) Reconstruction of seagrass dynamics: age determinations and associated tools for the seagrass ecologist. Mar Ecol Prog Ser 107:195-209

Duarte CM. Sand-Jensen K (1990a) Seagrass colonisation: patch formation and patch growth in Cymodocea nodosa. Mar Ecol Prog Ser 65:193-200

Duarte CM, Sand-Jensen K (1990b) Seagrass colonisation: biomass development and shoot demography in Cymodocea nodosa patches. Mar Ecol Prog Ser 67:97-103

Duarte CM, Sand-Jensen K (1996) Nutrient constraints on establishment from seed and on vegetative expansion of the Mediterranean seagrass Cymodocea nodosa (Ucria) Aschers. Aquat Bot 54:279-286

Durako MJ, Moffler MD (1987) Factors affecting the reproductive ecology of Thalassia testudinum (Hydrocharitaceael. Aquat Bot 27:79-95

Erickson RO, Michelini FJ (1957) The plastochron index. Am J Bot 44:297-305

Fonseca MS (1996) Scale dependence in the study of seagrass systems. In: Kuo J, Phillips RC, Walker DI, Kirkman H (eds) Seagrass biology: proceedings of an international workshop. Sciences UWA, Perth, p 95-104

Fonseca MS, Zieman JC, Thayer GW, Fisher JS (1983) The role of current velocity in structuring seagrass (Zostera marina L.) meadows. Estuar Coast Shelf Sci 17: $367-380$

Hastings HM. Sugihara G (1993) Fractals: a user's guide for the natural sciences. Oxford University Press, Oxford

Irlandi EA, Ambrose WG Jr, Orlando BA (1995) Landscape ecology and the marine environment: how spatial configuration of seagrass habitat influences growth and survival of the bay scallop. Oikos 72:307-313

Kotz S, Johnson NL (1985) Encyclopaedia of statistical sciences, Vol 6. Wiley \& Sons, New York, p 568-575

Marbà N, Cebriản J, Enriquez S, Duarte CM (1994) Migration of large scale sub aqueous bedforms measured using seagrasses (Cymodocea nodosa) as tracers. Limnol Oceanogr 39:126-133

Marbà N, Duarte CM (1995) Coupling of seagrass (Cymodocea nodosal patch dynamics to subaqueous dune migration. J Ecol 83:381-389

McRoy CP, Lloyd DB (1981) Comparative function and stability of macrophyte-based ecosystems. In: Longhurst AR (ed) Analysis of marine ecosystems. Academic Press, London, $p$ 473-489

Meinesz A, Lefevre JR (1984) Régénération d'un herbière de Posıdonia oceanica quarante années après sa destruction par une bombe dans la rade de Villefranche (AlpesMaritimes, France). In: Boudouresque CF, Jeudy de Grissac A, Olivier J (eds) International Workshop on Posidonia oceanica beds. G.I.S. Posidonie, Marseille, p 39-44

Meltzer MI, Hastings HM (1992) The use of fractals to assess the ecological impact of increased cattle population: case study from the Runde Communal Land, Zimbabwe. J Appl Ecol 29:635-646 
Olesen B, Sand-Jensen K (1994) Patch dynamics of eelgrass Zostera marina. Mar Ecol Prog Ser 106:147-156

Patriquin DG (1975) Migration of blowouts in seagrass beds at Barbados and Carriacou, West Indies, and its ecological and geological implications. Aquat Bot 1:163-189

Pérez M (1989) Fanerógamas marinas en sistemas estuáricos: producción, factores limitantes y algunos aspectos del ciclo de nutrientes. PhD thesis, University of Barcelona

Pérez M, Duarte CM, Romero J, Sand-Jensen K, Alcoverro T (1994) Growth plasticity in Cymodocea nodosa stands: the importance of nutrient supply. Aquat Bot 47:249-264

Pickett STA, Cadenasso ML (1995) Landscape ecology: spatial heterogeneity in ecological systems. Science 269 . $331-332$

Robbins BD, Bell SS (1994) Seagrass landscapes: a terrestrial approach to the marine subtidal environment. Trends Ecol

Editorial responsibility: Otto Kinne (Editor),

Oldendorf/Luhe, Germany
Evol 9(8):301-304

Sand-Jensen K, Madsen TV (1992) Patch dynamics of the stream macrophyte, Callitriche cophocarpa. Freshwat Biol $27: 277-282$

Schroeder M (1991) Fractals, chaos, power laws. WH Freeman, New York

Vidondo B. Prairie YT, Blanco JM, Duarte CM (1997) Some aspects of the analysis of size spectra in aquatic ecology. Limnol Oceanogr 42(1):184-192

Wiens JA (1989) Spatial scaling in ecology. Funct Ecol 3 385-397

Winiwarter P, Cempel C (1992) Life symptoms: the behavior of open systems with limited energy dissipation capacily and evolution. Syst Res 9(4):9-34

Zeide B (1993) Primary unit of the tree crown. Ecology 74(5). $1598-1602$

Submitted. May 13, 1997; Accepted: August 15, 1997 Proofs received from author(s): October 17, 1997 